\title{
Interrelationship between family history of alcoholism and generational status in the prediction of alcohol dependence in US Hispanics
}

\author{
K. G. Chartier ${ }^{1,2 *}$, N. S. Thomas ${ }^{1}$ and K. S. Kendler ${ }^{2,3,4}$ \\ ${ }^{1}$ Virginia Commonwealth University School of Social Work, Richmond, VA, USA \\ ${ }^{2}$ Department of Psychiatry, Virginia Commonwealth University School of Medicine, Richmond, VA, USA \\ ${ }^{3}$ Virginia Commonwealth University, Virginia Institute for Psychiatric and Behavioral Genetics, Richmond, VA, USA \\ ${ }^{4}$ Department of Human and Molecular Genetics, Virginia Commonwealth University School of Medicine, Richmond, VA, USA
}

\begin{abstract}
Background. Both a family history of alcoholism and migration-related factors like US $v$. foreign nativity increase the risk for developing alcohol use disorders in Hispanic Americans. For this study, we integrated these two lines of research to test whether the relationship between familial alcoholism and alcohol dependence changes with successive generations in the United States.
\end{abstract}

Method. Data were from the waves 1 and 2 National Epidemiologic Survey on Alcohol and Related Conditions (NESARC). Subjects self-identified Hispanic ethnicity $(N=4122 ; n=1784$ first, $n=1169$ second, and $n=1169$ third or later generation) and reported ever consuming $\geqslant 12$ drinks in a 1-year period. A family history of alcoholism was assessed in first- and second-degree relatives. Analyses predicting the number of alcohol dependence symptoms were path models.

Results. Alcohol dependence symptoms were associated with a stronger family history of alcoholism and later generational status. There was a significant interaction effect between familial alcoholism and generational status; the relationship of familial alcoholism with alcohol dependence symptoms increased significantly with successive generations in the United States, more strongly in women than men. Acculturation partially mediated the interaction effect between familial alcoholism and generational status on alcohol dependence, although not in the expected direction.

Conclusions. Familial alcoholism interacted with generational status in predicting alcohol dependence symptoms in US Hispanic drinkers. This relationship suggests that heritability for alcoholism is influenced by a higher-order environmental factor, likely characterized by a relaxing of social restrictions on drinking.

Received 25 March 2015; Revised 10 December 2015; Accepted 11 December 2015; First published online 29 September 2016

Key words: Alcohol dependence, family history of alcoholism, genexenvironment interaction, generational status, Hispanic Americans.

\section{Introduction}

A family history of alcoholism and certain sociocultural factors are both associated with an increased risk for developing alcohol use disorders. Alcoholism in a biological family member is a strong positive predictor of alcoholism in other family members. It is associated, in the general population, with an earlier onset of drinking (Dawson, 2000) and a more severe symptom profile of alcoholism (Moss et al. 2007). Familial alcoholism encompasses both family environment and genetic effects. Parental alcoholism is

\footnotetext{
* Address for correspondence: K. G. Chartier, Ph.D., Virginia Commonwealth University School of Social Work, 1000 Floyd Avenue, P.O. Box 842027, Richmond, VA 23284-1030, USA.

(Email: kgchartier@vcu.edu)
}

associated with known risk factors for alcohol use disorders in offspring, including reduced family communication and parental monitoring, parental separation, and harsh discipline practices (Thompson et al. 2008; Chartier et al. 2010; Waldron et al. 2013). Likewise, adoption and twin studies and the large-scale study of alcohol dependent probands and their family members support a genetic basis for alcoholism (Edenberg \& Foroud, 2006; Verhulst et al. 2015).

An individual's overall risk of alcohol dependence is known to have a significant genetic component. The heritability of alcohol use disorders based on twin and adoption studies is estimated to be 0.49 (Verhulst et al. 2015). Some recent gene-finding studies have identified specific genes that are related to alcohol dependence such as GABRA2 (Covault et al. 2004; Edenberg et al. 2004) and ADH1B (Bierut et al. 2012; 
Gelernter et al. 2014). Few studies, however, have examined measured genes for alcohol dependence, or for that matter the heritability of alcoholism in Hispanic American samples (Konishi et al. 2003, 2004; Harden et al. 2013; Norden-Krichmar et al. 2014). One family study of heart disease in Mexican Americans estimated the heritability of alcohol use disorders at 30\% (Olvera et al. 2011), while a Cuban twin study estimated it to be 57\% (Marcheco-Teruel et al. 2013).

Conversely, an extensive body of research in US Hispanics supports the importance of socio-cultural factors in the development of alcohol dependence. Factors related to migration and US residency are important. Alcohol use patterns of immigrants tend to be similar to those of their country of origin, while those of later generations or individuals more integrated into the US culture are more consistent with overall patterns observed in the population (Gilbert \& Cervantes, 1986). US nativity and more time spent in the United States predict a greater frequency of alcohol use or greater risk for developing a substance use disorder (Alderete et al. 2000; Alegria et al. 2006, 2007; Borges et al. 2011). Alegria et al. (2007) reported a greater risk of substance use disorders for secondgeneration Hispanics compared to first-generation Hispanics, and a particularly elevated risk for thirdgeneration Hispanics. The acculturation process, i.e. changes in preferences, behaviors, and values/norms that may occur after an individual or group enters a new culture, is one possible mechanism to explain these relationships (Caetano, 1987; Markides et al. 1988; Lara et al. 2005). More time in the United States and later generational status are general indices of greater exposure to the dominant US culture. Acculturative changes linked to more drinking in US Hispanics include the lower retention of traditional family values and a loosening of gender roles for women (Gil et al. 2000; Unger et al. 2002; Telzer et al. 2014).

The aim of the current study was to integrate these two traditionally separate lines of research (i.e. geneticand migration-related factors) to examine their interactive effect in predicting alcohol dependence in US Hispanics. This study focused on a family history of alcoholism and generational status (first, second, or third or later) as indicators for these two larger categories of factors, and used data from the National Epidemiologic Survey on Alcohol and Related Conditions (NESARC). The family history study design is an initial method for examining the familial aggregation for heritability in the general population. Dawson et al. (1992) findings about familial alcoholism among drinkers in the US population are consistent with patterns of genetic inheritance. The odds of alcohol dependence, relative to having no family history, were highest in persons with densely affected families (i.e. alcoholism in first-, second-, and third-degree relatives; 167\%) and higher in those with alcoholism in first-degree relatives only $(86 \%)$ than in second- and third-degree relatives only (45\%). Dick \& Kendler (2012) suggest that genetic effects can be muted in protective environments and become more pronounced in adverse environments. Peer relationships, parental monitoring, and adverse childhood events are often studied as examples of protective and adverse micro-level factors that interact with genetic variants (Dick \& Kendler, 2012).

Studies, using different designs, also provide evidence that higher-order socio-cultural factors can influence the heritability of alcoholism and related disorders. Hasin et al. (2002) and Higuchi et al. (1994) reported that the protective effects of alcohol metabolism-related gene variants were weaker in individuals belonging to heavy-drinking cultures in Israel and younger cohorts in Japan, respectively. Dick et al. (2001), using data from a Finnish twin study, showed larger effects for genetic factors on alcohol consumption in communities with greater migration. Migrant studies also provide a helpful design for understanding the influence of environmental and genetic factors. For example, if the rate of a disorder changes in a migrating group to the level observed in the new country this suggests an environmental effect, while retaining a similar rate to that in the original country suggests a possible genetic effect or that environmental factors are less relevant (Gonzalez Burchard et al. 2005). Breslau et al. (2011) identified migration to the United States as a high risk environment for conduct disorders, showing that the risk of conduct disorder was higher in children of Mexican-born parents who were raised in the United States and even higher for Mexicans born in the United States compared to Mexicans from migrant households who were raised in Mexico. Blackson et al. (2015), in a sample of young adult immigrants, showed that parental substance use problems in their country of origin predicted more severe alcohol use problems for subjects both pre- and post-immigration to the United States. This study did not address a critical question relevant to the current study, which is whether the strength of the association between parental substance use problems and offspring alcohol problems increased over the pre- and post-immigration periods.

Therefore, the current study posed the question: Does the relationship between familial alcoholism and alcohol dependence symptoms change with successive generations in the United States? We hypothesized that the strength of the family history of alcoholism $\times$ alcohol dependence symptoms relationship would be stronger in later generations. The interaction effect between familial alcoholism and generational status presumably tests whether, in Hispanic American drinkers, increasing 
exposure to the dominant US culture is associated with a larger impact of family history on risk for alcohol dependence. In a follow-up analysis, we tested whether acculturation mediated this relationship between familial alcoholism and generational status with alcohol dependence symptoms, and if there were differences in these relationships by gender. We expected that the interaction effect would be partially explained by changes in acculturation, i.e. the stronger effect for familial alcoholism in later generations would be mediated by increases in acculturation. The current study may provide preliminary evidence that migration-related factors are important for further study in genexenvironment analyses with measured genes.

\section{Method}

\section{Sample}

The study included $N=4122$ Hispanic subjects who participated in the wave 1 NESARC and were re-interviewed at wave 2 (Chen et al. 2010). These subjects were drinkers, reporting to have ever consumed $\geqslant 12$ alcoholic drinks in a 1 -year period at wave 1 and/or since the last interview at wave 2. NESARC respondents were a representative sample of the US adult population, including citizens and non-citizens. The wave 1 target population was non-institutionalized civilians, aged $\geqslant 18$ years, residing in all 50 states and the District of Columbia. This included persons living in households and non-institutional group quarters. Wave 1 used a multistage stratified design and oversampled Non-Hispanic Black and Hispanic households and young adults (ages 18-24 years) in households. Details about the sample design are provided in Grant et al. (2003b). Briefly, households were selected at higher rates if they had at least one Hispanic resident and, if no Hispanics, at least one Black resident based on information from the Census 2000/2001 Supplementary Survey. The NESEARC data, therefore, provided ample subjects for this ethnic group-based analysis. Wave 2 used the same respondents as wave 1 with the exception of those who were ineligible (e.g. institutionalized, deceased, or on active duty in the armed forces), refused, or could not be located. The wave 2 response rate was $86.7 \%$, and accounting for the wave 1 response rate yielded an overall cumulative survey response rate of $70.2 \%$. Sampling weights for the wave 2 data set account for the design characteristics of the NESARC survey, nonresponse, and sample attrition.

\section{Data collection}

Data collection for wave 1 occurred in 2001-2002 and for wave 2 in 2004-2005. Trained and experienced lay interviewers from the U.S. Census Bureau administered respondent interviews. The survey instrument was computerized with software that included built-in skip, logic, and consistency checks. Surveys were conducted either in English or Spanish based on respondent's preference in face-to-face household settings. Supervisors re-contacted a random $10 \%$ of all respondents by telephone for quality control purposes.

\section{Measures}

The alcohol dependence symptoms variable was a criteria count from 0 to 7 . The Alcohol Use Disorder and Associated Disabilities Interview Scheduled - DSM-IV Version (AUDADIS-IV) was used to assess alcohol dependence. In the present study, a measure of lifetime alcohol dependence symptoms was created by combining wave 1 questions assessing if each symptom had ever occurred and wave 2 questions assessing each symptom since the last interview. Alcohol dependence diagnoses within the AUDADIS-IV have been found to be reliable (Grant et al. 1995), as well as alcohol symptom counts within the measure (Grant et al. 2003a).

A family history of alcoholism was a mean weighted score of first- and second-degree relatives reported to be an alcoholic or problem drinker. Alcoholism/problem drinking was defined as having a physical or emotional problem related to drinking; having problems (related to drinking) with a spouse, other family member, or friends, with the police, or at work or school; and spending a lot of time drinking or being hung over (Chen et al. 2006). Respondents answered a series of questions about their biological relatives; the current score included 12 relative types, i.e. mother, father, brothers, sisters, and maternal and paternal grandmothers, grandfathers, aunts, and uncles. Some relative types were coded 0, 1 (no/yes; e.g. mother and paternal grandfather) and others were a proportion (e.g. the number of alcoholic brothers out of the number brothers who lived to be 10 years old). The current study weighted responses for first-degree relatives with a value of 1 and second-degree relatives with a value of 0.5 . Weighted responses were summed and divided by the number of relative types. A higher family history score indicated a stronger family history of relatives with alcoholism or who engage in problem drinking.

Generational status had three levels: first generation (individuals not born on the US mainland); second generation (US-born with at least one foreign-born parent); and third or later generation (US-born and both parents US-born). This measure was based on each subject's responses to three questions asking: (1) if the subject was born in the United States, (2) the 


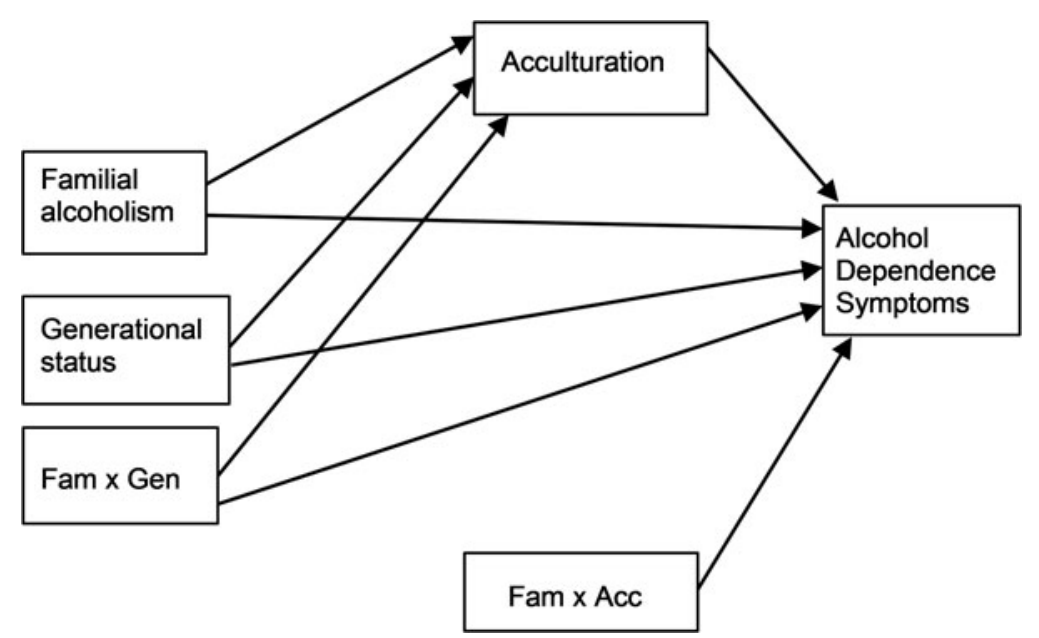

Fig. 1. Mediated moderation model for the familial alcoholism by generational status interaction and acculturation in predicting alcohol dependence symptoms.

country where the subject's mother was born, and (3) the country where the subject's father was born.

Number of years lived in the United States combined a continuous response question for the number of years of US residence with a question about whether the respondent (no/yes) was born in the United States. The variable was coded as follows: (1) 0-5 years; (2) 6-10 years; (3) 11-20 years; (4) $\geqslant 21$ years; and (5) US-born, based on Alegria et al. (2007).

NESARC assessed acculturation using an 11-item scale. These items, according to Ruan et al. (2008), were derived from both the Brief Acculturation Rating Scale-II for Mexican Americans (ARSMA-II) and the East Asian Acculturation Measure (EAAM). The scale included questions related to individual's language preferences in a variety of contexts (e.g. reading and speaking, in childhood, at home, in thought, speaking with friends, etc.) as well as questions related to the ethnicity of participant's friend/peer groups. A sum-score of individual items, ranging from 1 to 5 (higher numbers reflect higher levels of acculturation), was calculated with a possible total score of 55 . This measure was shown to have high test-retest reliability (ICC $=0.79)$ (Ruan et al. 2008).

Demographic variables included gender $(1=$ men, $2=$ women), age (20-29, 30-39, 40-49, 50-59, $\geqslant 60$ years), and level of education, i.e. the highest grade or year of school completed (coded as: less than high school; completed high school or GED; some college education; and a $\geqslant 4$-year college degree).

\section{Data analysis}

The descriptive statistics for the sample were estimated using Stata's (release 13) SVY command (StataCorp, 2013). Mplus version 7 (Muthén \& Muthén, 2009) was used to conduct the path analyses. All analyses accounted for the NESARC's weight, cluster, and stratification information. The path models were fit using the maximum likelihood estimator with robust standard errors (MLR) to non-linearity and nonindependence of observations due to cluster sampling.

We tested three models: (1) estimating the main effects of familial alcoholism and generational status to alcohol dependence symptoms; (2) estimating the familial alcoholism $\times$ generational status interaction effect; and (3) estimating the mediation effects through level of acculturation. We used a probability value of $<0.05$ in determining statistical significance for all tests. All models controlled for the associations of age, gender, and level of education. These models were also re-estimated with the variable 'number of years lived in the United States' substituted for generational status. A plot of the predicted linear relationship between familial alcoholism and alcohol dependence symptoms by generational status was constructed in Stata to assist in the interpretation of the interaction effect.

The mediation model was analyzed using the framework of Preacher et al. (2007) and Edwards \& Lambert (2007) for testing a direct effect and first stage moderation model, called mediated moderation by some. To avoid bias in the familial alcoholism by generational status interaction, we regressed alcohol dependence symptoms on the interaction between familial alcoholism and acculturation (Yzerbyt et al. 2004). This model (see Fig. 1) investigated whether the interaction between familial alcoholism and generational status predicted acculturation (the mediating variable), and in turn, predicted the number of alcohol dependence symptoms. Mediation effects (i.e. indirect effects) via level of acculturation were estimated using the product of coefficients approach and delta standard errors 
Table 1. Characteristics of the total sample and by first, second, and third or later generations

\begin{tabular}{|c|c|c|c|c|c|}
\hline & \multirow{2}{*}{$\begin{array}{l}\text { Total } \\
(N=4122)\end{array}$} & \multicolumn{3}{|c|}{ Generational status } & \multirow[b]{2}{*}{$p^{*}$} \\
\hline & & 1 st $(n=1784)$ & 2nd $(n=1169)$ & 3 rd $(n=1169)$ & \\
\hline No. of alcohol dependence symptoms & $1.82(0.044)$ & $1.38(0.063)$ & $2.04(0.065)$ & $2.42(0.094)$ & $<0.001^{\mathrm{a}} ;<0.001^{\mathrm{b}}$ \\
\hline Familial alcoholism score & $0.06(0.002)$ & $0.04(0.001)$ & $0.06(0.001)$ & $0.09(0.005)$ & $<0.001^{\mathrm{a}} ;<0.001^{\mathrm{b}}$ \\
\hline Level of acculturation & $34.06(0.362)$ & $25.43(0.213)$ & $39.32(0.212)$ & $45.05(0.461)$ & $<0.001^{\mathrm{a}} ;<0.001^{\mathrm{b}}$ \\
\hline Male & 64.00 & 72.42 & 58.32 & 53.93 & $<0.001$ \\
\hline Age, years & & & & & $<0.001$ \\
\hline $20-29$ & 25.41 & 19.27 & 35.18 & 27.41 & \\
\hline $30-39$ & 29.08 & 31.54 & 26.49 & 27.03 & \\
\hline $40-49$ & 22.55 & 24.15 & 18.24 & 23.74 & \\
\hline $50-59$ & 12.51 & 14.41 & 9.07 & 12.31 & \\
\hline$\geqslant 60$ & 10.44 & 10.64 & 11.02 & 9.51 & \\
\hline Education & & & & & $<0.001$ \\
\hline$<$ High school & 29.73 & 44.15 & 19.31 & 13.13 & \\
\hline High school & 24.31 & 21.91 & 23.92 & 29.12 & \\
\hline Some college & 29.94 & 18.84 & 40.08 & 40.72 & \\
\hline$\geqslant 4$ years college & 16.01 & 15.10 & 16.70 & 17.04 & \\
\hline
\end{tabular}

Statistics are mean (standard error) or percentage.

${ }^{*} p$ values are for comparisons by generational status (categorical variables used $\chi^{2}$ tests; and continuous variables used $F$ tests); ${ }^{a} p$ values for the means difference between 1 st and $3 \mathrm{rd}$ or later generations; ${ }^{\mathrm{b}} p$ values for the means difference between 2nd and 3rd or later generations.

Table 2. Main and interaction effects models in predicting alcohol dependence symptoms $(N=4056)$

\begin{tabular}{llr}
\hline & $\beta$ (S.E.) & $p$ value \\
\hline Main effects model & & \\
Familial alcoholism & $0.272(0.022)$ & $<0.001$ \\
$\quad$ Generational status & $0.193(0.022)$ & $<0.001$ \\
Interaction effects model & & \\
$\quad$ Familial alcoholism & $0.146(0.062)$ & 0.019 \\
Generational status & $0.156(0.026)$ & $<0.001$ \\
Fam $\times$ Gen & $0.149(0.066)$ & 0.024 \\
\hline
\end{tabular}

$\beta$, Standardized coefficient; S.E., standard error.

All models controlled for gender, age, and level of education.

(Morgan-Lopez \& MacKinnon, 2006; Muthén \& Muthén, 2009). The mediation model was estimated in the total sample, as well as separately in men and women.

\section{Results}

About half (48.52\%) of these Hispanic American drinkers were first generation (i.e. born outside of the US mainland), with the remaining evenly split between the second $(25.16 \%)$ and third or later $(26.32 \%)$ generations. Most subjects reported residence in the United States of $\geqslant 21$ years $(20.61 \%)$ or were US-born $(51.48 \%)$, while fewer reported residing in the United States: $0-5(3.50 \%), 6-10(7.42 \%)$, and $11-20(17.00 \%)$ years. Other study variables were estimated stratified by generational status (see Table 1) and showed significant differences across generation groups. Compared with the third or later generation, first- and secondgeneration subjects reported a lower number of alcohol dependence symptoms as well as a weaker family history of alcoholism. Not surprisingly, third or later generation subjects reported a higher level of acculturation than the two other groups. First-generation subjects were more likely to be male and to have a lower level of education. There were significant age differences across generations, for example, the first generation had a lower percentage of 20- to 29-year-olds.

Models testing main and interaction effects (Table 2) controlled for gender, age, and level of education. In the main effect model, a stronger family history of alcoholism and a later generational status were associated with more alcohol dependence symptoms. Results for the interaction model showed a significant joint effect for familial alcoholism with generational status in predicting alcohol dependence symptoms. The interaction is plotted in Fig. 2; the association of familial alcoholism with alcohol dependence symptoms was stronger with successive generations. 


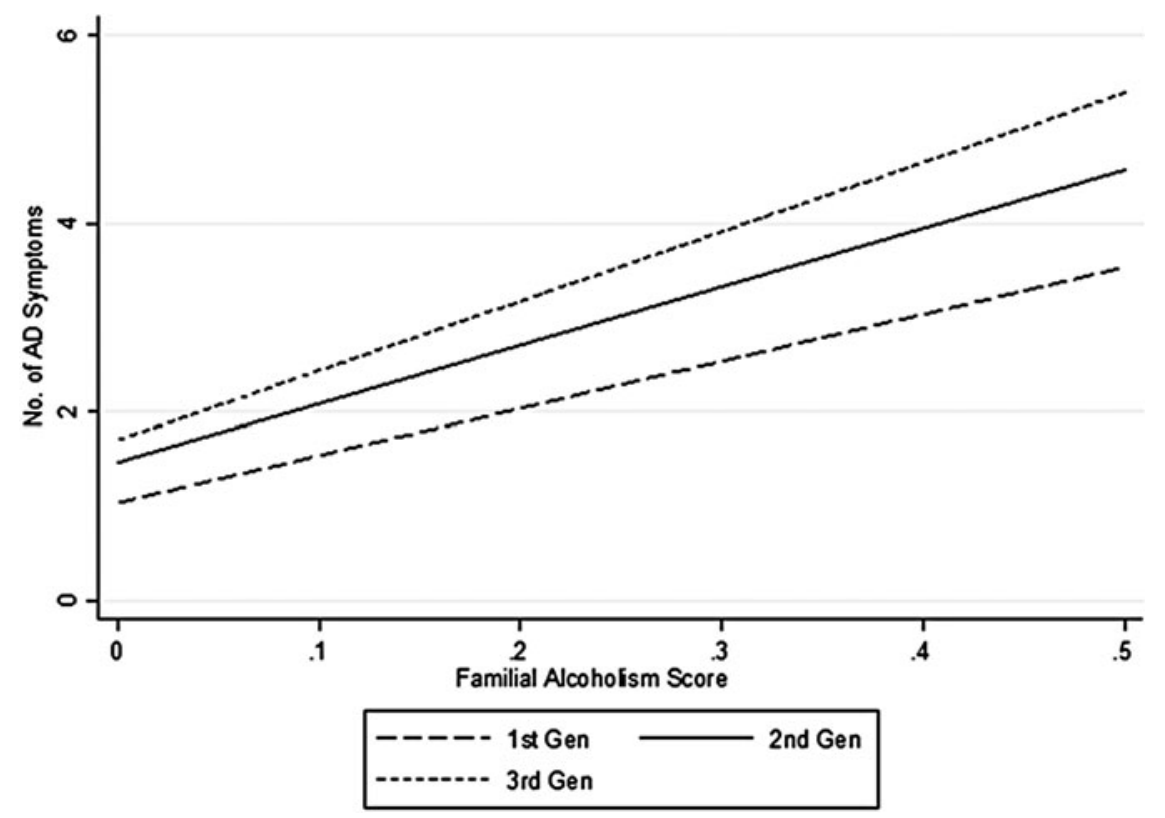

Fig. 2. Family history of alcoholism by generational status with alcohol dependence symptoms.

The interaction model was extended by examining level of acculturation as a mediator for the interaction between familial alcoholism and generational status (Table 3). In the total sample, the interaction was in part mediated by level of acculturation. This indirect effect was negative; it had a stronger relationship in earlier $v$. later generations. We calculated unstandardized conditional indirect effects to estimate the mediated path in each generation group (Preacher et al. 2007). Conditional indirect effects were statistically significant in the first and second generations, respectively $(B=0.230$, S.E. $=0.101, p=0.023$ and $B=$ 0.133 , s.E. $=0.063, p=0.033)$, but not in the third or later generation $(B=0.036$, S.E. $=0.048, p=0.456)$. The mediated path via acculturation was not statistically significant when tested separately in men only and women only. Furthermore, the direct effect from the familial alcoholism $\times$ generational status interaction to alcohol dependence symptoms was statistically significant in the total sample and in women only, but was not significant in men only.

The same models were re-analyzed with years of living in the United States. The results were comparable to those reported for generational status, with significant positive main effects for familial alcoholism $(\beta=0.286$, s.E. $=0.023, p<0.001)$ and years living in the United States $(\beta=0.191$, S.E. $=0.022, p<0.001)$, as well as a significant interaction $(\beta=0.255$, s.E. $=0.103, p=$ 0.013) in the prediction of alcohol dependence symptoms. Similarly, in the mediation model, there was a significant direct effect for the interaction to alcohol dependence symptoms observed in the total sample $(\beta=0.298$, s.E. $=0.134, p=0.027)$ and in women $(\beta=0.514$, S.E. $=0.200, \quad p=0.010)$, but not in men $(\beta=0.319$, S.E. $=0.178, p=0.074)$. However, the interaction was not mediated by level of acculturation in either the total sample or the men only and women only samples.

\section{Conclusions}

The current study showed that familial alcoholism risk is vulnerable to the environmental effects of generational status and length of residency in the United States in predicting alcohol dependence symptoms. Greater exposure to the US culture was associated with larger effects for familial alcoholism in Hispanic American drinkers. US population studies show that migration and longer US residency are associated with higher rates of drinking and risk for substance use disorders in Hispanic Americans (Alderete et al. 2000; Alegria et al. 2006, 2007; Borges et al. 2011). We found that the interaction between familial alcoholism and generational status was significant in women, but not in men. This is not entirely surprising. Caetano (1987) and Zemore (2007) report, along with other studies, a stronger and more consistent positive relationship in women than men between alcohol consumption and assimilation into the US culture. Findings from Unger et al. (2002) support the relationship between shifting gender norms and drinking for Hispanic American women. They report that alcohol use is more likely in females who have low endorsement of traditional roles (i.e. machismo and 


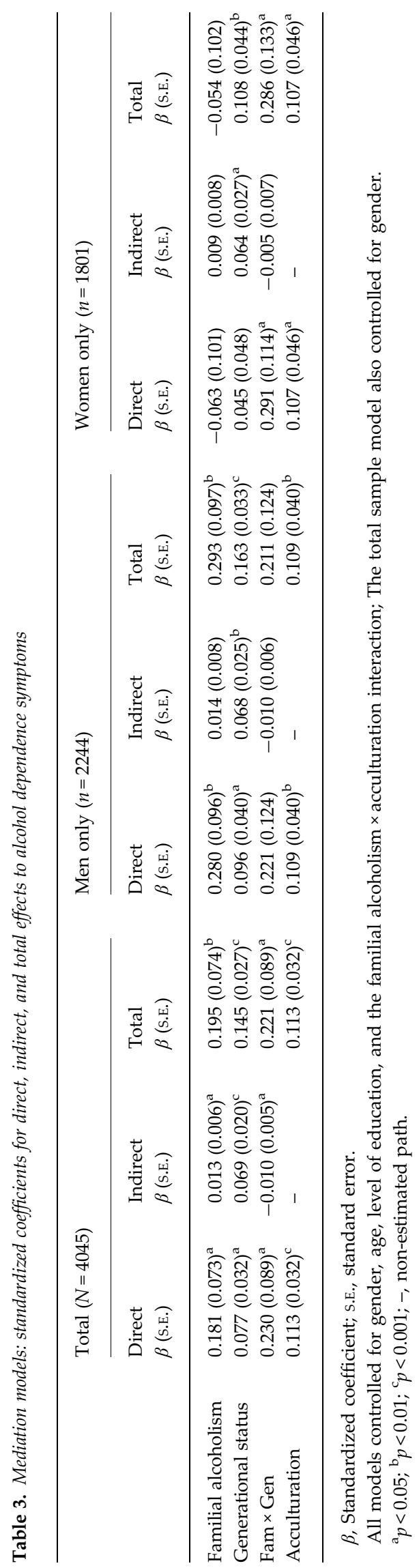

marianismo) for men and women. Furthermore, Zemore (2005) reported that greater drinking volume was associated with more positive drinking norms in Hispanic women.

These results are congruent with prior models of genetic propensity and environmental social control (Dick \& Kendler, 2012). That is, environments characterized by relaxed social restrictions and increased access to alcohol are associated with higher heritability of substance use. This evidence primarily comes from twin studies. For example, Dick et al. (2001) and Rose et al. (2001) report larger effects for genetic factors on alcohol consumption in urban $v$. rural environments where access is likely higher and social constraints weaker. Specific to women, Kendler et al. (2000) reported that genetic influences on tobacco use increased over time in Swedish cohorts, as gender restrictions on tobacco use eased. Other genexenvironment studies point to the roles that family relationships and peers play in controlling access to alcohol. Low parental monitoring, high peer deviance, and greater alcohol availability are associated with increased genetic influences on alcohol use in youth (Kendler et al. 2011).

Social control mechanisms linked to acculturation may help explain the interaction between familial alcoholism and generational status in predicting alcohol dependence symptoms. High acculturation in Hispanic Americans has been identified as a risk factor for alcohol dependence and heavier drinking (Caetano, 1987; Markides et al. 1988; Caetano et al. 2009). Weaker social constraints on drinking may occur because of a loosening of traditional gender roles and drinking norms for women (e.g. as reported by Unger et al. 2002; Zemore, 2005). Acculturative changes in family values and relationships may also occur and are predictive of drinking. Gil et al. (2000) reported a relationship between heavy alcohol use and the reduction of traditional values like parental respect and familism in Hispanic youth. Telzer et al. (2014) also reported a negative relationship between lower values for family obligation and substance use.

We found some evidence for a mediational path via acculturation. This indirect effect was not particularly large and was only found in the total sample for the interaction between familial alcoholism and generational status. It was also unexpectedly negative, indicating a stronger positive relationship with alcohol dependence symptoms in earlier $v$. later generations. Therefore, this path did not explain the stronger relationship of familial alcoholism in later generations. Instead, higher acculturation played a larger mediational role when the risks associated with generational status and familial alcoholism were not already high (i.e. in the first and then second generations). It could 
be that direct measures of our hypothesized mechanisms, i.e. cultural values/norms, gender, and family changes, would more effectively explain the identified interaction effect; acculturation in the current study measured language preference and ethnic composition of friend/peer groups. It might also be that other related changes are important, e.g. discrimination experiences might offer another mediational mechanism. Later generational status is associated with a higher likelihood of reporting discrimination experiences (Perez et al. 2008), including in women (Viruell-Fuentes, 2007), and the relationship between discrimination experiences and substance use disorder risk is stronger in US-born individuals than those immigrating during childhood (Savage \& Mezuk, 2014).

Our findings underscore the importance of targeting prevention efforts to second and particularly third or later generation Hispanic American women with a family propensity for alcoholism. The interaction effect points to environmental factors linked to migration as important for strengthening the association between familial alcoholism and alcohol dependence symptoms; however, the specific mechanisms that explain this effect still require additional study. The current study was limited by the variables that were available in the data set. The NESARC did not measure traditional family values, gender role norms, or social drinking norms. There were also limitations to the family history study design. The familial alcoholism score could not distinguish family environment from genetic effects on alcohol dependence symptoms, and we could not be sure that our generational groups, which migrated at different times and likely for different reasons, were genetically comparable (Rutter et al. 2001). Some studies in Mexican populations report an association between genetic diversity and migration status (Gonzalez Burchard et al. 2005), and in other populations both genetic diversity and migration are influenced by such factors as educational attainment (Abdellaoui et al. 2015). Additionally, while we did examine gender differences in our study, we did not compare our results across Hispanic subgroups. There is some evidence that the relationship between US nativity and substance use disorders is more consistent in Mexican Americans compared to other Hispanic American groups (Alegria et al. 2006, 2008), which may offer an additional question for future research.

A strength of this study is the novel way that we tested the interactive effect between a higher-order social factor and genetic mechanisms, using US population data and a familial alcoholism score as a latent measure of genetic effects. We suggest that the family history design, despite its limitations, is a valuable interim approach as other options for testing these interaction effects in Hispanic Americans are currently limited. To our knowledge, there are no epidemiologic studies with focuses on ethnic minority populations and socio-cultural predictors of alcohol dependence that also collect genetic data. As well, studies of measured genes typically do not collect macro-level social measures and, therefore, genexenvironment interaction analyses are often restricted to examining micro-level factors (e.g. adverse childhood events) and sociodemographic variables. Studies of genexenvironment interactions using measured genes in Hispanic populations are very limited. One study, in a sample of Mexican Americans, showed that having $\leqslant 12$ years of education paired with a risk genotype at OPRM1 - a $\mathrm{Mu}$ opioid receptor gene - was associated with increased heavy drinking (Du \& Wan, 2009).

Gonzalez Burchard et al. (2005) identified Hispanics as an unique population in which to examine the complex interrelationships between social, economic, and genetic factors. First, individuals of Hispanic or Latino descent are diverse in terms of-geography and socio-cultural factors - their countries of origin, immigration histories, socioeconomic conditions, and acculturation experiences (Alvarez et al. 2007). They are also a recent genetically admixed population, with European, African, and Native American ancestries, which may provide opportunities for identifying genetic risk variants (Gonzalez Burchard et al. 2005). Ancestry proportions (European, African, and Native American) have been associated with asthma severity in Hispanic samples (Salari et al. 2005), and alcohol dependence in other populations (Zuo et al. 2009). However, these analyses should be conducted with great attention due to the reported relationship between genetic ancestry and socio-economic status in a Puerto Rican sample (Choudhry et al. 2007); this further emphasizes the importance of examining genetic data jointly with socio-cultural and other environmental factors, including in genexenvironment interactions.

As studies move from latent heritability techniques to specified genes in the study of higher order genexenvironment interactions, genetic variants related to alcohol metabolism may be an initial target, because of previous results reported by Hasin et al. (2002) and Higuchi et al. (1994). The relationships between these genes and alcohol dependence require exposure to alcohol, and, therefore, may interact with environmental conditions that control access to alcohol. Other study designs could involve multiple genetic variants through the use of genetic ancestry or admixture mapping approaches (Choudhry et al. 2007) or polygenic risk scores (Salvatore et al. 2014) to examine genexenvironment interactions in association with alcohol dependence. A better understanding of the genetic architecture of alcohol dependence may be required 
before polygenic scores out preform family history (Yan et al. 2014). Opportunities to test higher order measured genexenvironment interactions may require the added collection of genetic data in coordination with ongoing epidemiologic studies. The public availability of the wave 3 NESARC data, which includes a collection of genetic samples, may facilitate these analyses.

In conclusion, this study used a novel approach to examine the interaction between generational status (and years of US residency) and familial alcoholism in predicting alcohol dependence symptoms in Hispanic American drinkers. Our analysis involved US population data, a latent measure of genetic effects, and a higher order genexenvironment interaction. We showed that the relationship between familial alcoholism and alcohol dependence was stronger with successive generations in the United States, and that this effect was also stronger in women compared to men. This interaction effect was in part mediated by acculturation processes characterized by language or friend/peer groups preferences, but may be better explained by changes in family values, gender roles, and social drinking norms or potentially in discrimination experiences that are also associated with increased risks for alcohol use disorders.

\section{Acknowledgements}

This work was supported by the National Institute on Alcohol Abuse and Alcoholism of the National Institutes of Health (K.C., K01AA021145; and K.K., P50AA022537).

\section{Declaration of Interest}

None.

\section{References}

Abdellaoui A, Hottenga JJ, Willemsen G, Bartels M, van Beijsterveldt T, Ehli EA, Davies GE, Brooks A, Sullivan PF, Penninx BW, de Geus EJ, Boomsma DI (2015). Educational attainment influences levels of homozygosity through migration and assortative mating. PLOS ONE 10, e0118935.

Alderete E, Vega WA, Kolody B, Aguilar-Gaxiola S (2000). Effects of time in the United States and Indian ethnicity on DSM-III-R psychiatric disorders among Mexican Americans in California. Journal of Nervous and Mental Disease 188, 90-100.

Alegria M, Canino G, Shrout PE, Woo M, Duan N, Vila D, Torres M, Chen CN, Meng XL (2008). Prevalence of mental illness in immigrant and non-immigrant U.S. Latino groups. American Journal of Psychiatry 165, 359-369.
Alegria M, Canino G, Stinson FS, Grant BF (2006). Nativity and DSM-IV psychiatric disorders among Puerto Ricans, Cuban Americans, and non-Latino Whites in the United States: results from the National Epidemiologic Survey on Alcohol and Related Conditions. Journal of Clinical Psychiatry 67, 56-65.

Alegria M, Mulvaney-Day N, Torres M, Polo A, Cao Z, Canino G (2007). Prevalence of psychiatric disorders across Latino subgroups in the United States. American Journal of Public Health 97, 68-75.

Alvarez J, Jason LA, Olson BD, Ferrari JR, Davis MI (2007). Substance abuse prevalence and treatment among Latinos and Latinas. Journal of Ethnicity in Substance Abuse 6, 115-141.

Bierut LJ, Goate AM, Breslau N, Johnson EO, Bertelsen S, Fox L, Agrawal A, Bucholz KK, Grucza R, Hesselbrock V, Kramer J, Kuperman S, Nurnberger J, Porjesz B, Saccone NL, Schuckit M, Tischfield J, Wang JC, Foroud T, Rice JP, Edenberg HJ (2012). ADH1B is associated with alcohol dependence and alcohol consumption in populations of European and African ancestry. Molecular Psychiatry 17, $445-450$.

Blackson TC, De La Rosa M, Sanchez M, Li T (2015). Latino immigrants' biological parents' histories of substance use problems in their country of origin predict their pre- and post-immigration alcohol use problems. Substance Abuse 36, 257-263.

Borges G, Breslau J, Orozco R, Tancredi DJ, Anderson H, Aguilar-Gaxiola S, Mora MEM (2011). A cross-national study on Mexico-US migration, substance use and substance use disorders. Drug and Alcohol Dependence 117, $16-23$.

Breslau J, Borges G, Saito N, Tancredi DJ, Benjet C, Hinton L, Kendler KS, Kravitz R, Vega W, Aguilar-Gaxiola S, Medina-Mora ME (2011). Migration from Mexico to the United States and conduct disorder: a cross-national study. Archives of General Psychiatry 68, 1284-1293.

Caetano R (1987). Acculturation and drinking patterns among United-States Hispanics. British Journal of Addiction 82, 789-799.

Caetano R, Ramisetty-Mikler S, Rodriguez LA (2009). The Hispanic Americans Baseline Alcohol Survey (HABLAS): the association between birthplace, acculturation and alcohol abuse and dependence across Hispanic national groups. Drug Alcohol Dependence 99, 215-221.

Chartier KG, Negroni LK, Hesselbrock MN (2010). Strengthening family practices for Latino families. Journal of Ethnic \& Cultural Diversity in Social Work 19, 1-17.

Chen CM, Yi HY, Dawson DA, Stinson FS, Grant BF (2010). Alcohol Use and Alcohol Use Disorders in the United States, a 3-Year Follow-up: Main Findings from the 2004-2005 Wave 2 National Epidemiologic Survey on Alcohol and Related Conditions (NESARC). National Institute on Alcohol Abuse and Alcoholism: Bethesda, MD.

Chen CM, Yi HY, Falk DE, Stinson FS, Dawson DA, Grant BF, Hilton ME, Breslow RA (2006). Alcohol Use and Alcohol Use Disorders in the United States: Main Findings from the 2001-2002 National Epidmiologic Suvery on Alcohol and Related Conditions (NESARC). National Institute on Alcohol Abuse and Alcoholism: Bethesda, MD. 
Choudhry S, Seibold MA, Borrell LN, Tang H, Serebrisky D, Chapela R, Rodriguez-Santana JR, Avila PC, Ziv E, Rodriguez-Cintron W, Risch NJ, Burchard EG (2007). Dissecting complex diseases in complex populations: asthma in Latino americans. Proceedings of the American Thoracic Soceity 4, 226-233.

Covault J, Gelernter J, Hesselbrock V, Nellissery M, Kranzler HR (2004). Allelic and haplotypic association of GABRA2 with alcohol dependence. American Journal of Medical Genetics Part B: Neruopsychiatric Genetics 129B, 104-109.

Dawson DA (2000). The link between family history and early onset alcoholism: earlier initiation of drinking or more rapid development of dependence? Journal of Studies on Alcohol 61, 637-646.

Dawson DA, Harford TC, Grant BF (1992). Family history as a predictor of alcohol dependence. Alcoholism: Clinical and Experimental Research 16, 572-575.

Dick DM, Kendler KS (2012). The impact of gene-environment interaction on alcohol use disorders. Alcohol Research 34, 318-324.

Dick DM, Rose RJ, Viken RJ, Kaprio J, Koskenvuo M (2001). Exploring gene-environment interactions: socioregional moderation of alcohol use. Journal of Abnormal Psychology 110, 625-632.

Du Y, Wan YJ (2009). The interaction of reward genes with environmental factors in contribution to alcoholism in Mexican Americans. Alcoholism: Clinical and Experimental Research 33, 2103-2112.

Edenberg HJ, Dick DM, Xuei X, Tian H, Almasy L, Bauer LO, Crowe RR, Goate A, Hesselbrock V, Jones K, Kwon J, Li TK, Nurnberger Jr. JI, O'Connor SJ, Reich T, Rice J, Schuckit MA, Porjesz B, Foroud T, Begleiter H (2004). Variations in GABRA2, encoding the alpha 2 subunit of the GABA(A) receptor, are associated with alcohol dependence and with brain oscillations. American Journal of Human Genetics 74, 705-714.

Edenberg HJ, Foroud T (2006). The genetics of alcoholism: identifying specific genes through family studies. Addiction Biology 11, 386-396.

Edwards JR, Lambert LS (2007). Methods for integrating moderation and mediation: a general analytical framework using moderated path analysis. Psychological Methods 12, $1-22$.

Gelernter J, Kranzler HR, Sherva R, Almasy L, Koesterer R, Smith AH, Anton R, Preuss UW, Ridinger M, Rujescu D, Wodarz N, Zill P, Zhao H, Farrer LA (2014). Genome-wide association study of alcohol dependence:significant findings in African- and European-Americans including novel risk loci. Molecular Psychiatry 19, 41-49.

Gil AG, Wagner EF, Vega WA (2000). Acculturation familism, and alcohol use among Latino adolescent males: longitudinal relations. Journal of Community Psychology 28, 443-458.

Gilbert MJ, Cervantes RC (1986). Patterns and practices of alcohol use among Mexican Americans: a comprehensive review. Hispanic Journal of Behavioral Sciences 8, 1-60.

Gonzalez Burchard E, Borrell LN, Choudhry S, Naqvi M, Tsai HJ, Rodriguez-Santana JR, Chapela R, Rogers SD,
Mei R, Rodriguez-Cintron W, Arena JF, Kittles R, Perez-Stable EJ, Ziv E, Risch N (2005). Latino populations: a unique opportunity for the study of race, genetics, and social environment in epidemiological research. American Journal of Public Health 95, 2161-2168.

Grant BF, Dawson DA, Stinson FS, Chou PS, Kay W, Pickering R (2003a). The Alcohol Use Disorder and Associated Disabilities Interview Schedule-IV

(AUDADIS-IV): reliability of alcohol consumption, tobacco use, family history of depression and psychiatric diagnostic modules in a general population sample. Drug and Alcohol Dependence 71, 7-16.

Grant BF, Harford TC, Dawson DA, Chou PS, Pickering RP (1995). The Alcohol-Use Disorder and Associated Disabilities Interview Schedule (AUDADIS) - reliability of alcohol and drug modules in a general-population sample. Drug and Alcohol Dependence 39, 37-44.

Grant BF, Kaplan K, Shepard J, Moore T (2003b). Source and Accuracy Statement for Wave 1 of the 2001-2002 National Epidemiologic Survey on Alcohol and Related Conditions. National Institute on Alcohol Abuse and Alcoholism: Bethesda, MD.

Harden KP, Tucker-Drob EM, Tackett JL (2013). The Texas Twin Project. Twin Research and Human Genetics 16, 385-390.

Hasin D, Aharonovich E, Liu X, Mamman Z, Matseoane K, Carr L, Li TK (2002). Alcohol and ADH2 in Israel: Ashkenazis, Sephardics, and recent Russian immigrants. American Journal Psychiatry 159, 1432-1434.

Higuchi S, Matsushita S, Imazeki H, Kinoshita T, Takagi S, Kono H (1994). Aldehyde dehydrogenase genotypes in Japanese alcoholics. Lancet 343, 741-742.

Kendler KS, Gardner C, Dick DM (2011). Predicting alcohol consumption in adolescence from alcohol-specific and general externalizing genetic risk factors, key environmental exposures and their interaction. Psychological Medicine 41, 1507-1516.

Kendler KS, Thornton LM, Pedersen NL (2000). Tobacco consumption in Swedish twins reared apart and reared together. Archives of General Psychiatry 57, 886-892.

Konishi T, Calvillo M, Leng AS, Feng J, Lee T, Lee H, Smith JL, Sial SH, Berman N, French S, Eysselein V, Lin KM, Wan YJ (2003). The ADH3*2 and CYP2E1 c2 alleles increase the risk of alcoholism in Mexican American men. Experimental and Molecular Pathology 74, 183-189.

Konishi T, Luo HR, Calvillo M, Mayo MS, Lin KM, Wan YJ (2004). ADH1B*1, ADH1C², DRD2 (-141C Ins), and 5-HTTLPR are associated with alcoholism in Mexican American men living in Los Angeles. Alcoholism: Clinical and Experimental Research 28, 1145-1152.

Lara M, Gamboa C, Kahramanian MI, Morales LS, Bautista DE (2005). Acculturation and Latino health in the United States: a review of the literature and its sociopolitical context. Annual Review of Public Health 26, 367-397.

Marcheco-Teruel B, Cobas-Ruiz M, Cabrera-Cruz N, Lantigua-Cruz A, Garcia-Castillo E, Lardoeyt-Ferrer R, Robaina-Jimenez Z, Fuentes-Smith E, Morales-Calatayud F, Lemus-Valdes MT, Portuondo-Sao M, Comas-Perez L, Perez-Crispi JM, Diaz-De Villal Villa T, Icart-Perera E, Jordan-Hernandez A, Lage-Castellanos A, Rabell-Piera S, 
de Llibre-Rodriguez JJ, Valdes-Sosa P, Valdes-Sosa M (2013). The Cuban Twin Registry: initial findings and perspectives. Twin Research and Human Genetics 16, 98-103.

Markides KS, Krause N, Mendes de Leon CF (1988). Acculturation and alcohol consumption among Mexican Americans: a three-generation study. American Journal of Public Health 78, 1178-1181.

Morgan-Lopez AA, MacKinnon DP (2006). Demonstration and evaluation of a method for assessing mediated moderation. Behavioral Research Methods 38, 77-87.

Moss HB, Chen CM, Yi HY (2007). Subtypes of alcohol dependence in a nationally representative sample. Drug Alcohol Dependence 91, 149-58.

Muthén L, Muthén B (2009). Mplus. Muthén \& Muthén: Los Angeles.

Norden-Krichmar TM, Gizer IR, Wilhelmsen KC, Schork NJ, Ehlers CL (2014). Protective variant associated with alcohol dependence in a Mexican American cohort. BMC Medical Genetics 15, 136-157.

Olvera R, Bearden C, Velligan D, Almasy L, Carless M, Curran J, Williamson D, Duggirala R, Blangero J, Glahn D (2011). Common genetic influences on depression, alcohol, and substance use disorders in Mexican-American families. American Journal of Medical Genetics Part B: Neuropsychiatric Genetics 156, 561-568.

Perez DJ, Fortuna L, Alegria M (2008). Prevalence and correlates of everyday discrimination among U.S. Latinos. Journal of Community Psychology 36, 421-433.

Preacher KJ, Rucker DD, Hayes AF (2007). Addressing moderated mediation hypotheses: theory, methods, and prescriptions. Multivariate Behavioral Research 42, 185-227.

Rose RJ, Dick DM, Viken RJ, Kaprio J (2001).

Gene-environment interaction in patterns of adolescent drinking: regional residency moderates longitudinal influences on alcohol use. Alcoholism: Clinical and Experimental Research 25, 637-643.

Ruan WJ, Goldstein RB, Chou SP, Smith SM, Saha TD, Pickering RP, Dawson DA, Huang B, Stinson FS, Grant BF (2008). The Alcohol Use Disorder and Associated Disabilities Interview Schedule-IV (AUDADIS-IV): reliability of new psychiatric diagnostic modules and risk factors in a general population sample. Drug and Alcohol Dependence 92, 27-36.

Rutter M, Pickles A, Murray R, Eaves L (2001). Testing hypotheses on specific environmental causal effects on behavior. Psychological Bulletin 127, 291-324.

Salari K, Choudhry S, Tang H, Naqvi M, Lind D, Avila PC, Coyle NE, Ung N, Nazario S, Casal J, Torres-Palacios A, Clark S, Phong A, Gomez I, Matallana H, Perez-Stable EJ, Shriver MD, Kwok PY, Sheppard D, Rodriguez-Cintron W, Risch NJ, Burchard EG, Ziv E (2005). Genetic admixture and asthma-related phenotypes in Mexican American and Puerto Rican asthmatics. Genetic Epidemiology 29, 76-86.

Salvatore JE, Aliev F, Edwards AC, Evans DM, Macleod J, Hickman M, Lewis G, Kendler KS, Loukola A, Korhonen T, Latvala A, Rose RJ, Kaprio J, Dick DM (2014). Polygenic scores predict alcohol problems in an independent sample and show moderation by the environment. Genes (Basel) 5 , 330-346.

Savage JE, Mezuk B (2014). Psychosocial and contextual determinants of alcohol and drug use disorders in the National Latino and Asian American Study. Drug and Alcohol Dependence 139, 71-78.

StataCorp (2013). Stata Survey Data Reference Manual: Release 13. Stata Press: College Station, TX.

Telzer EH, Gonzales N, Fuligni AJ (2014). Family obligation values and family assistance behaviors: protective and risk factors for Mexican-American adolescents' substance use. Journal of Youth and Adolescence 43, 270-283.

Thompson RG, Lizardi D, Keyes KM, Hasin DS (2008). Childhood or adolescent parental divorce/separation, parental history of alcohol problems, and offspring lifetime alcohol dependence. Drug and Alcohol Dependence 98, 264-269.

Unger JB, Ritt-Olson A, Teran L, Huang T, Hoffman BR, Palmer P (2002). Cultural values and substance use in a multiethnic sample of California adolescents. Addiction Research \& Theory 10, 257-279.

Verhulst B, Neale MC, Kendler KS (2015). The heritability of alcohol use disorders: a meta-analysis of twin and adoption studies. Psychological Medicine 45, 1061-1072.

Viruell-Fuentes EA (2007). Beyond acculturation: immigration, discrimination, and health research among Mexicans in the United States. Social Science and Medicine 65, 1524-1535.

Waldron M, Bucholz KK, Lynskey MT, Madden PA, Heath AC (2013). Alcoholism and timing of separation in parents: findings in a midwestern birth cohort. Journal of Studies on Alcohol and Drugs 74, 337-348.

Yan J, Aliev F, Webb BT, Kendler KS, Williamson VS, Edenberg HJ, Agrawal A, Kos MZ, Almasy L, Nurnberger Jr. JI, Schuckit MA, Kramer JR, Rice JP, Kuperman S, Goate AM, Tischfield JA, Porjesz B, Dick DM (2014). Using genetic information from candidate gene and genome-wide association studies in risk prediction for alcohol dependence. Addiction Biology 19, 708-721.

Yzerbyt VY, Muller D, Judd CM (2004). Adjusting researchers' approach to adjustment: on the use of covariates when testing interactions. Journal of Experimental Social Psychology 40, 424-431.

Zemore SE (2005). Re-examining whether and why acculturation relates to drinking outcomes in a rigorous, national survey of Latinos. Alcoholism: Clinical and Experimental Research 29, 2144-2153.

Zemore SE (2007). Acculturation and alcohol among latino adults in the united states: a comprehensive review. Alcoholism: Clinical and Experimental Research 31, 1968-1990.

Zuo L, Luo X, Listman JB, Kranzler HR, Wang S, Anton RF, Blumberg HP, Stein MB, Pearlson GD, Covault J, Charney DS, van Kammen DP, Price LH, Lappalainen J, Cramer J, Krystal JH, Gelernter J (2009). Population admixture modulates risk for alcohol dependence. Human Genetics 125, 605-613. 